\title{
A model approach
}

\author{
More development work is needed to help computer simulations inform economic policy.
}

V odels are everywhere in economics. They range from the pencil-and-paper equations used for academic analyses of market behaviour, to the computer forecasts used by central banks, such as the Bank of England and the US Federal Reserve System, to determine the likely effects of interest-rate adjustments.

But the reputation of economic models has been tarnished of late. Virtually none anticipated the global financial meltdown that began two years ago this summer (see pages 680 and 685). The fingerpointing seems likely to go on indefinitely: were the models flawed? Or were policy-makers at fault for ignoring the warnings?

What is clear is that economic models need to improve. The ability to run policy options through a believable set of 'what-if' scenarios could be useful to forestall future economic crises, and to inform debate, such as that over the labyrinthine efforts to reform the US health-care system.

The field could benefit from lessons learned in the large-scale modelling of other complex phenomena, such as climate change and epidemics (see page 687). Those lessons, taken together with lessons from the downturn, suggest an ambitious research agenda - not just for economists, but for psychologists, political and social scientists, computer researchers and more.

First, details matter. Government regulators rely on dynamic stochastic general equilibrium (DSGE) simulations, which can make sophisticated extrapolations of past economic data. But these models do little to incorporate information about the financial sector, which is where the current crisis began. Which company was entering into what kind of arrangements with another, for example, and how were they all interconnected? And most models don't even attempt to incorporate the psychological insights gained from behavioural economics, and so ignore shifting attitudes towards risk, and the spread of fear - both major contributors to the crisis. The comparatively few modelling efforts that do try to include these factors deserve support - and many more such efforts are needed.

Second, models should evolve through vigorous competition. As the articles in this issue show, advocates of agent-based modelling techniques, which represent each individual or company with an 'agent', claim that their programs can often account for economic phenomena much better than can DSGE simulations. Such claims need to be addressed empirically. The economics community should try to agree on a standard set of test cases analogous to those used by climate modellers, whose challenges can include being able to reproduce El Niño oscillations. Economic modellers should also consider adopting the modular architecture used in many climate models. This approach makes it easy to aggregate smaller models into more comprehensive simulations, while still allowing steady improvement in each piece. A sub-model for ocean circulation, say, can be switched for an alternative circulation module without changing anything else.

Third, modellers seeking to make a real difference in the world should concentrate on the tangible, immediate questions that decision-makers actually worry about. A good example to follow is that of pandemic planning, in which simulations are already in widespread use to help officials decide when to close schools and other public gathering places, and how best to mount a vaccination campaign. The simulations alone cannot answer such questions, nor can they replace judgement. But by helping officials frame the problem, organize the available information and identify which factors matter, they can make judgements better informed.

\section{Science under attack}

\section{Congress should stop playing politics with the peer-review process.}

$\mathrm{n}$ a depressingly familiar display of irresponsible politicking, the US House of Representatives has taken aim at three studies funded by the National Institutes of Health (NIH). Representative Darrell Issa (Republican, California) introduced an amendment killing the projects on 24 July, during a debate on the NIH's 2010 budget. The House passed the amendment by a voice vote.

Issa was unhappy that the studies looked at substance abuse and HIV risk behaviour, and that the subjects were outside the United States. One focused on Russian alcoholics, another on female sex workers in China and a third on female and transgender prostitutes in Thailand. All three passed muster with NIH peer reviewers, and together would cost about $\$ 5$ million over five years. Issa wanted that money to be spent at home, and complained that HIV had been heavily studied already. But his reasoning is specious: alcoholism, prostitution and HIV do not respect borders, and any behavioural information that could help slow the transmission of HIV is crucial. Some 33 million people are infected worldwide, and a vaccine is nowhere in sight.

Issa's tactic is not new. Since 2003, conservative House Republicans have tried at least five times to strip funding from peer-reviewed projects that drew their ire. Such meddling threatens to undermine the peer-review process as well as potentially eroding the public's trust that science is above politics.

Also worrying is the House Democrats' acquiescence to Issa's amendment. Democrats facing tough re-election bids hoped to dodge Republican attacks in media adverts in their home districts that might have resulted from opposing Issa. Their assumption is that the amendment can be quietly removed when House and Senate negotiators meet to square their versions of the NIH bill before a final vote on it. But Congress should renounce all tactics that undermine peer review - and cease indulging those who use them. 